Article

\title{
"This Is the Story of Community Leadership with Political Backing. (PM1)" Critical Junctures in Paralympic Legacy: Framing the London 2012 Disability Inclusion Model for New Global Challenges ${ }^{\dagger}$
}

\author{
Victoria Austin ${ }^{1, *}$, Kate Mattick ${ }^{1}$ and Cathy Holloway ${ }^{2}$ (1) \\ 1 Global Disability Innovation Hub Community Interest Company \& GDI Hub WHO Global Collaborating \\ Center for AT, University College London, London WC1E 6BT, UK; k.mattick@ucl.ac.uk \\ 2 UCL Interaction Centre \& GDI Hub WHO Global Collaborating Center for AT, University College London, \\ London WC1E 6BT, UK; c.holloway@ucl.ac.uk \\ * Correspondence: victoria.austin@ucl.ac.uk \\ + This work is dedicated to the memory of Margaret Hickish who sadly passed away during the research. \\ Margaret's spirit and energy drove much of what was possible for London 2012 and she is sadly missed, but \\ not forgotten. Her work and thinking continues to drive change and inspires her legacy every day.
}

check for updates

Citation: Austin, V.; Mattick, K.; Holloway, C. "This Is the Story of Community Leadership with Political Backing. (PM1)" Critical Junctures in Paralympic Legacy: Framing the London 2012 Disability Inclusion Model for New Global Challenges. Sustainability 2021, 13, 9253.

https://doi.org/10.3390/su13169253

Academic Editor: Alison McIntosh

Received: 15 July 2021

Accepted: 15 August 2021

Published: 18 August 2021

Publisher's Note: MDPI stays neutral with regard to jurisdictional claims in published maps and institutional affiliations.

Copyright: (C) 2021 by the authors. Licensee MDPI, Basel, Switzerland. This article is an open access article distributed under the terms and conditions of the Creative Commons Attribution (CC BY) license (https:// creativecommons.org/licenses/by/ $4.0 /)$.

\begin{abstract}
The London 2012 Paralympic Games was called "the most successful Paralympic Games ever" (by the then-President of the IPC), and it saw more athletes from more countries than ever before compete and become global heroes for the first time in a redeveloped part of East London which also hosted "the most accessible Olympic Games ever" that summer. However, the model used to design and deliver disability inclusion for London 2012, and its legacy, has never been explicitly written up. This paper presents new primary evidence from first-hand research from those who were involved; retrospectively framing the London 2012 Disability Inclusion Model such that it might be usable and developed for other global disability challenges. We used an adapted Delphi methodology, through four rounds: beginning with an initial hypothesis and testing through semistructured interviews with ten key players in the London 2012 disability inclusion approach. Using thematic analysis with consensus building surveys and workshops we came to a settled unanimous agreement on the 12-step London 2012 Disability Inclusion Model comprising three parts: (Get ready) community-led mission setting, (Get set) essential building blocks and (Go) enabling a culture of success. The model is presented here, alongside a narrative on its uniqueness and replicability to other major programs, as a public good. We welcome its active use, testing and adaption by others in service of disability innovation for a fairer world.
\end{abstract}

Keywords: disability inclusion; Paralympic Games; disability innovation; London 2012; major programme management; equality mainstreaming; disability justice

\section{Introduction}

Disability inclusion necessitates proactive efforts to ensure everybody has an independent and equitable opportunity to meaningfully participate in the activities of their choosing [1-3]. Furthermore, disability justice is not a minority concern. There are more than a billion disabled people worldwide, and impairment is something which affects most people's family right now and will impact all of us over our lifetime. The United Nations Convention on the Rights of Persons with Disabilities (UNCRPD) enshrines human rights of all disabled people [4], and in 2015 the Sustainable Development Goals (SDG's) recognised disability inclusion for the first time with the call to 'leave no-one behind'. Increasingly, governments, non-governmental agencies and businesses alike are seeking to develop and implement policy and practice which enables greater social inclusion for disabled people (In this paper, Disabled People is used in line with the Social Model of 
Disability in the UK, though please note the UN uses 'Persons with Disabilities' as is common in North America) [5]. Eighty percent of the disabled people in the world live in low resource settings in the Global South [3] with a projected growth of this number due to an increase in population age, there is the ever-pressing need to critically evaluate how best to approach disability inclusion to build a societies where we all can flourish. Despite this, we lack case studies of how disability inclusion can be done well-in the literature and in practice. For this reason, we set out to undertake this research using one the most recognised cases of 'disability inclusion done well'.

The London 2012 Paralympic Games was called 'the greatest Paralympic Games ever' (by the then-President of the IPC) [6] (p. 4), and it saw more athletes from more countries than ever before compete and become global heroes for the first time in a redeveloped part of East London which also hosted 'the most accessible Olympic Games ever' (ibid.) that summer. The Inclusive Design Standards [7] developed for the London 2012 Games were adopted as best practice in the UK and are now being tested globally [8]. The Olympic and Paralympic Games do not happen in a vacuum [9], and there are limitations to their impact for the average disabled and non-disabled person $[9,10]$ of course. Especially as we look at who has been affected most by COVID-19 [11] it would be wrong to suggest their world has been on a linear, solely upwards trajectory since London. However, the cracks of possibility opened up by London 2012 have enabled a deeper focus on disability inclusion - certainly in the world of sports and major events, since then [12].

This paper does not seek to address how far or for how long London 2012 delivered a step change in disability inclusion. Rather, it seeks to address the fact that the model used to design and deliver disability inclusion for London 2012, and its legacy, has never been explicitly written up, as previous research has acknowledged, with this paucity of evidence about the legacy of the Paralympic games leading to calls for more research in this field [13]. This paper presents new primary evidence from first-hand research from those that were involved, retrospectively framing the London 2012 Disability Inclusion model such that it might be usable and developed for other global disability challenges.

In this context, this paper seeks first to explore current approaches to disability inclusion through grey and academic literature, both within the UK and international sphere, where the Paralympic Games is then discussed as an example of a disability inclusion movement with a reflective focus on the London 2012 games. Second, a hypothesis framework for disability inclusion is proposed, based on the researcher's insights and experience. Third, this is then tested through a four-step adapted Delphi methodology working with new evidence from a team of ten experts who were directly involved in delivering London 2012. Using content and thematic analysis and consensus building surveys and workshops, a settled unanimous agreement is arrived at. Finally, the paper then presents this 12-step London 2012 Disability Inclusion Model comprising three parts; (Get ready) community-led mission setting, (Get set) essential building blocks and (Go) enabling a culture of success. The model is presented alongside a narrative on its uniqueness and replicability to other major programs as a public good. We welcome its active use, testing and adaption by others in service of disability innovation for a fairer world.

\section{Background and Policy Context}

\subsection{The UK Equality Legislation}

The UK Equality Act 2010 is the most up to date anti-discrimination act in the UK making it unlawful to discriminate against a person based on disability (replacing the 1995 Disability Discrimination Act). The Equality Duty (previously Disability Equality Duty) is an accompanying document to the Equality Act which places duty on public bodies and organisers of public functions to meet the needs of all individuals through policy, employment and service delivery. The Duty encourages a proactive approach to disability inclusion and enables parties to recognise their responsibility in promoting equality and removing barriers for the benefit of both their organisation and the wider community [14]. 


\subsection{The Paralympic Games}

The Paralympic Games has a historical aim of promoting inclusion enshrined in the Paralympic Values of determination, equality, inspiration and courage. The Games' origins date back to 1948 when the first event was held at Stoke Mandeville Spinal Cord Centre in the UK led by neurosurgeon Sir Ludwig Guttman, who believed that sport was not only necessary to promote recovery, but could also address negative attitudes about disability [15].

In 1989, the International Paralympic Committee (IPC) was formed to ensure successful delivery of the games, support members, develop parasport and promote social inclusion. With the Paralympics now the third largest major sporting event in the world (after the Olympics and FIFA Football World Cup), and disability making its way up the global policy agenda, the IPC now takes its position as a global leader in promoting social inclusion more seriously than ever before [16]. In their 2019-2022 report, the IPC focused their third strategic priority on 'social transformation through the promotion of an inclusive society for all'. Within this third priority, the committee have set 8 objectives that focus on specific areas related to: engaging stakeholders, mainstreaming day-to-day disability issues, building international partnerships across government and non-government organisations, developing indicators to measure impact of Paralympics and advance implementation of the UNCRPD. Targeted outcomes are proposed to support in measuring the success of the strategy over the 4 year period [16]. Para sporting events can create opportunities to leverage national and international disability inclusion priorities [17]. This summer, the Tokyo 2020 Paralympics will see the launch of the biggest global movement of disability human rights in history - a ten year journey to disability inclusion, led by the IPC, called \#WeThe15 [18]. This new energy and focus around disability inclusion was supercharged by London 2012.

\subsection{London 2012}

In its bid to host the 2012 games, the London Organising Committee for the Olympic and Paralympic Games 2012 (LOCOG) planned for "the most ... inclusive Paralympic Games ever staged" [19] (p. 42) with new accessible venues and transport infrastructure. Eight specific commitments were developed alongside the aims which capitalised on the UK being the home of the Paralympics and committed to a legacy that was focused on inclusion [19].

The Olympic Delivery Authority (ODA) were the named public authority who would be legally responsible under the UK Equality Act to ensure an inclusive approach to the Games was adopted. This was significant as UK Equality Legislation is among the most comprehensive in the world with the Equality Act 2010 consolidating nine disparate pieces of previous legislation in a single Public Sector Equality Duty [20]. The ODA were responsible to ensure all individuals who participated in competing, spectating or working for the Games, were considered in the planning process.

To uphold their responsibility under the Equality Act 2010, the ODA produced an integrated equality scheme 2009-2012, writing "we ... want to use the power of the Games to inspire change and leave a sustainable legacy" setting a goal to "deliver real and practical outcomes for equality and diversity" [21] (p. 1). The ODA laid out their duty to equality legislation in a strategic plan for inclusive design, employment and business opportunities, targeted community engagement and internal organisation capabilities. Both the Mayor of London and its delivery agency, the London Legacy Development Corporation (previously called the Olympic Park Legacy Company), also held public sector Equality Duty Commitments and published relevant strategies with similar commitments; with the latter committing to "Deliver a lasting legacy from the Paralympic games which promotes disability sport" [22] (p. 5).

A joint report by the UK Government and the Mayor of London in 2013, detailed that $81 \%$ of people surveyed thought that the Games had a positive impact on how disabled people are viewed by the British Public and committed to increased funding for disability sport, and accessibility [23]. It also detailed some of the many major sporting events attracted to London because of the success of London 2012, many of which like the 
Rugby World Cup and the World Athletics Championships, as well as the annual National Paralympic Day Festival, had disability sports elements built in for the first time. Oxford Economics predicted that by 2030 East London (home of the 2012 Games) would have net $£ 4.5 \mathrm{bn}$ to the UK's finances, expecting to accommodate half of London's growth in jobs [24].

While this paper does not set out to justify or evaluate the impact of London 2012 on disability inclusion, it is worth noting for context some of the achievements of the Games in London, as recognised by the IPC. For the first time the games were positioned as a high-performance sporting event to the media and broadcasters, every Olympic Partner also signed up as a Paralympic sponsor, Paralympians became TV and media stars, the Games attracted a record breaking 4237 athletes from 164 countries completing 503 medal events across 20 sports to sold out venues where 2.7 million tickets had been sold and there were 15 countries competing in the Paralympics for the first time. The Games was beamed to over 100 countries reaching 3.8 billion people, watching 251 World and 314 Paralympic records broken. In his closing speech in the Olympic Stadium with hundreds of millions watching, Lord Coe said that people would never think of disability the same way again. One-third of UK adults said they changed their view, with $65 \%$ of people agreeing that the Paralympics had changed perceptions of disability more broadly. [25].

Authors writing post-games have particularly paid tribute to the influential media campaign, led by Channel 4, and hailed it as successful in not only raising the profile of para-athletes but also as having a profound impact on the public's perception of disability, setting a benchmark for the future [25-27]. However, this is also a view which is subject to challenge with some viewing the superhuman/"supercrip" narrative as reinforcing the performative nature of ableist stereotypes of normality which only assign value to "productive", societally recognised things (sporting success, economic contribution) [28]. Further, it is vital not to overstate the impact of the Paralympic Games. As argued by some, the apparent success of London 2012 should not be used to overshadow the difficulties faced by 'ordinary' disabled people in everyday life [29], especially in the context of the subsequent welfare changes that were made in the UK.

More than $11 \mathrm{~m}$ people in the UK watched the Opening Ceremony which was channel $4^{\prime}$ s biggest audience for a decade, and was filled with Disabled artists, directors, creators and volunteers creating a spectacle of the type never before seen, with a core message of real inclusion [25]. This was unprecedented, though as Brittain and Beacom argued, it is important to state that "sports mega events [like the Paralympics] do not take place in a vacuum. They are subject to wider social, economic and political dynamics ... [which] can work for or against the legacy process in unexpected ways" [9] (p. 515).

It is our intention in this paper only to convince the reader that the operationalisation of the disability inclusion objectives for London 2012 and its legacy was valid enough to warrant interest in a framed model, not that the legacy of the event is beyond debate. It is therefore relevant to set this in the international context.

\subsection{Disability Inclusive International Development}

Outside of the Paralympics, the UN and its partners offer disability inclusion approaches, the most notable of which is the UNCRPD. The UNCRPD brings together human rights instruments from across the spectrum into one document for the first time and highlights the role international development organisations have in collaborating with state parties and through the designing of programmes that are accessible and inclusive of disabled people, including through the use of General Comments. [4] The 2017 Kazan Action Plan also offers a unifying guidelines for integrity in sport [30] bringing forward new initiatives in policy to inspire better practice.

The United Nations launched its new Disability Inclusion Strategy in 2019, pledging a commitment for the system-wide strengthening of disability inclusion through a twin-track approach, combining both mainstreaming and tailored disability specific programming throughout their organisation structure and program delivery [1]. The strategy includes 
both a benchmark policy and an accountability framework with four core areas and fifteen indicators: leadership, strategic planning and management, inclusiveness and organisational culture. All UN entities are required to report annually on the indicators, and each UN agency sets out its own profile of work and priorities.

In response to the first Global Disability Summit, held in London-on Queen Elizabeth Olympic Park-in 2018, co-hosted by the Governments of the UK, Kenya and the International Disability Alliance (IDA), increasingly coordinated and ambitious global commitments have been made on disability inclusive development [31]. Global development giants like the Asian Development Bank (ADB) have published disability inclusion commitments with a forthcoming framework [32], and the World Bank's strategy recognises their role in addressing the socioeconomic inequality disabled people face driven through setting a goal of "ending extreme poverty and promoting shared prosperity" [33] (p. 3).

Most NGOs and some commercial stakeholders have also offered responses to these frameworks. CBM, a large global NGO and leader on disability issues, deserves recognition for producing a guide to disability inclusion in development for those that deliver programs in international organisations. They propose guiding principles that include awareness of disability, participation of people with disabilities in decision making-fostering relationships between people with and without disabilities helping to breakdown stigma, comprehensive accessibility - the removal of barriers and a twin track approach of disability specific and mainstreaming strategies [34]. The guide also advocates for the collection of data and sharing of successes and is considered a useful tool that supports progress in this space.

This approach to mainstreaming disability inclusion as a strategy for development and promotion of equality is well cited in the literature, has roots within gender inclusion [35] and is increasingly well adopted at policy level. Miller and Albert [36] discuss key lessons that could be taken from gender mainstreaming and applied to disability mainstreaming within development [36]. While they are cross-cutting issues, there is a need to appoint a person responsible for championing the specific issues and have time-bound goals within program delivery for each.

There is commonality across the international and national legislation as well as the IPC strategic plan when setting principles and frameworks for disability inclusion. Usually, key concepts highlighted include the need for clear objectives with measurable outcomes, accessibility and the removal of barriers, partnerships with disabled people and community engagement alongside strong leadership. They often include what is referred to [1] as a 'twin track' approach of mainstreaming inclusion across all initiatives and taking targeted action or making specific investments to address disability issues. We now turn to look in more detail at previous studies.

\subsection{Previous Studies of Disability Inclusion}

The strategies highlighted above demonstrate a commitment to disability inclusion within the global policy and program space. However, there is an increased need for research on the effectiveness and impact of implementing such disability inclusion programs to know what works [37]. Here, we summarise some examples selected for their relevance in drawing out the key themes.

A 2011 paper reported on the implementation of the Disability Equality Duty across public sector organisations in the UK. Findings suggest the Disability Equality Duty had prompted policies tackling discrimination and organisations demonstrated awareness of disability mainstreaming. A key strength of the Disability Equality Duty being its legal grounds which make it unlawful to not comply, with executives held accountable if they do not. However, the paper revealed limited evidence to suggest disability equality was fully embraced and integrated throughout the organisations analysed. Authors concluded an improved need for a systematic approach to identify and address inequality [35].

From the Global South, a recent study explored equity and inclusion of Malawi's disability mainstreaming and implementation plan, developed in response to the UNCRPD. 
Researchers analysed the policy to review how inclusive the process of developing the policy and plan was, and whether people with disabilities were consulted in the process. Although the authors highlight the good intentions of policy makers, there was little evidence or clarity provided of the involvement of people with disabilities in its development. The paper concludes with the need to involve and engage with people with disabilities in the development of policy to ensure effective implementation [38].

Zambia has updated and implemented new policies to align with UNCRPD. Qualitative research explored 24 disability policy stakeholder perspectives of a new system of Disability Focal Point Persons (FPP) implemented within Zambia ministries under guidance of article 33 of the UNCRPD. FPPs were initiated to ensure widespread engagement and implementation of disability mainstreaming initiatives. The Panel Members interviewed felt the FPP system provided a hopeful avenue for mainstreaming disability in government, but initial introduction was flawed and ineffective. There was a lack of role and system clarification and inconsistent appointing of FPPs across ministries, where some lacked power to influence change [39]. This highlighted the need for effective leadership within disability inclusion approaches.

Humanitarian disaster risk reduction is a global priority. The Sendai Framework 2015-2030 has been cited as more inclusive of people with disabilities than the framework it replaced. It explicitly mentions the involvement of people with disabilities and advocacy organisations as stakeholders within development and implementing of disaster risk reduction policies, with specific mentions to inclusive design and accessibility as approaches $[33,40,41]$. However, a paper reviewing the historic and current frameworks to participation in disaster relief concluded that the Sendai Framework mentioned community engagement fewer times than previous disaster relief documentation, fearing there was a move away from valuing community-led input [42].

Taiwan published research about the implementation of the Sendai Framework for persons with disabilities. Using priorities of the Sendai framework they developed questionnaires and sent them to central ministries, agencies and local governments. They found a top-down approach and advocated for bottom-up strategies that focus on participation, empowerment, communication and consultation with stakeholders. As advocated for in the Sendai framework they developed recommendations to be taken forward with targeted communication strategies and planning for people with disabilities through disaster risk reduction cycle [43].

A 2020 review of research about implementation of the Sendai Framework for inclusion of people with disabilities found variability in implementation. Suggesting this was in part due to cultural attitudes about people with disability and the need for negative cultural attitudes to alter to allow for full inclusion of people with disabilities [41]. Further research is required to share good practice about integrating people with disabilities in global initiatives.

A paper analysing the challenges of involving disabled people in poverty reduction strategies in Uganda found Disabled People's Organizations were disengaged working alongside government in developing policy as well as a lack of statistical data about the current situation that DPO's could use in lobbying government for change. Recommendations for change, based on the experience in Uganda included improving communications between government and DPO's, equipping DPO's with skills that enable them to advocate for change, and the removal of physical and environmental barriers, ensuring meeting places are accessible [39].

There is neither space nor scope to provide a full review of all work on disability inclusion across the multidisciplinary literature here. However, the above gives the flavour of the themes we take forward into our study: mainstreaming and targeted intervention, increasing strategic focus at a regional and global level and a patchy implementation and dis-census of method across the globe despite an increasing consensus on the importance of disability inclusion. The number of times engagement of disabled people, and the leadership 
by disabled people comes up, along with the need for bottom-up strategies is a useful reflection for this research in particular.

\section{Materials and Methods}

\subsection{Research Aims}

The aim of this research was to retrospectively frame the London 2012 Disability Inclusion approach, with a focus on the activity by the core agencies involved. The key questions we set out to address were as follows:

- What approach was used by London 2012 to embed disability inclusion?

- How replicable is the London 2012 model to other similar programs?

- To what extent can London 2012 be considered a 'critical juncture'?

To answer these aims we worked with ten experts who has been central in leading the London 2012 approach, and employed a four-stage adapted Delphi process, explained below.

\subsection{The Delphi Methodology Overview}

The Delphi method is an exploratory systematic approach to group communication which aims to reach consensus about a specific, multifaceted problem that is often undefined [44-47]. It was chosen to meet the research aims precisely because disability inclusion approaches are under researched in major programs. Because of this, the expert opinion accessed for this study was pivotal in documenting the approaches taken in London 2012, and reaching a collective judgement was felt to be a helpful contribution to the field. Furthermore, the aim of the research was to consider if a model could be developed for use with future programs and the Delphi methodology has been found to be effective for new guideline and model development previously $[48,49]$.

When using a Delphi method, a group of identified experts interact through a series of rounds on a complex issue, that they hold knowledge and have experience of, in order to critique and come to a consensus. Delphi methods are used to provide up-todate information from current knowledge of experts where research may otherwise be lacking or unpublished [50,51]. The specific features and design of Delphi studies are highly varied and can use both qualitative and quantitative approaches [46,47]. Key characteristics are identified as iteration, controlled feedback, anonymity of responses and group consensus [52]. The first round can be used to openly explore the topic area via open-ended questions which generate themes and also collect feedback on pre-defined themes which are developed from literature, prior experience and practice $[44,51,53]$.

In the subsequent rounds of the Delphi process, the experts are asked to review and provide feedback on the collated findings from the preceding rounds which are presented back to them anonymously. The process continues until consensus is reached, which is usually $2-3$ rounds. What is considered consensus must be agreed by the researchers at the start of the study, based on the aims of research $[44,46]$. Consensus building workshops, after rounds, can be used to develop and refine new models and theory $[48,54,55]$. Workshops can minimise the common critique (that it does not allow for debate [56]) of the Delphi methodology by holding space for respondents to elaborate on their thoughts. We set out how we adapted this model below.

\subsection{Adapted Delphi Methodology for This Study}

\subsubsection{Hypothesis A-The Initial Hypothesis}

The methods for this study were designed using an adapted Delphi technique. First, an initial hypothesis was developed by the research team, based on first-hand experience of working on London 2012 to deliver disability inclusion, VA, building out from the grey literature available-including the disability commitments in the $2005 \mathrm{bid}$, and the subsequent published material as part of the London 2012 'learning legacy' [57]. The research was then conducted as follows: 
- $\quad$ Round 1: semi-structured interviews were conducted by a trained qualitative researcher, VA, with 10 individuals ('Panel Members') who worked in the London 2012 organisations at the time. The Panel Members valued the items in Hypothesis A using a Likert scale. Thematic analysis conducted by KM and VA led to a modification of Hypothesis A and the development of Hypothesis B.

- $\quad$ Round 2: a digital survey led by KM, offered the new Hypothesis B to the Panel Members who scored the Hypothesis B and answered some open questions about the uniqueness and replicability of the London 2012 approach.

- $\quad$ Round 3: a consensus building workshop presented results from the survey, focusing the discussion on the two items that did not have consensus backing ( $75 \%$ or less of the respondents scoring the item as important) as well as the order. The meeting was facilitated by VA and KM, and the group were able to further refine the Hypothesis by discussing any items that had not reached consensus in round 2 and 3 . A couple of items were refined and merged, with new items added, until the whole group was happy with the 2012-12 step disability inclusion model-hypothesis C. The workshop then discussed applicability to future programs.

- Round 4: Thematic analysis of the qualitative data from the previous interviews, survey and workshop was used to build out the 'explainers' of each of the 12-stem 2012 Inclusion Model 'items'. Thematic analysis was used to enhance the answers and consider the replicability question.

\subsubsection{Data Collection and Analysis}

The data was collected and analysed in 4 rounds as set out above. Interviews and workshops were conducted virtually and recorded via Microsoft Teams or Zoom software. Data were stored within the secure UCL system as per the data protection protocol. Nvivo 12 was used for thematic analysis of the qualitative data, following Braun and Clarke [58]. The online survey used in round 2 was conducted via Microsoft forms. All Panel Members were given a pseudonym, presented as a number (PM 1-10).

Three researchers took part in the analysis, with the first researcher (VA) undertaking the interviews and leading the workshops, and the second researcher (KM) transcribing and evaluating the data. VA and KM developed themes and codes which were then reviewed by the third researcher $(\mathrm{CH})$ to ensure reliability and robustness. Member checking was also possible between the stages, due to the methods used, and participants were given the opportunity of feedback before and during workshops. This all supported the data saturation strategy, and the workshop/panel concluded with consensus across all participants.

\subsubsection{Determining Group Consensus}

There is no standardised agreement in the literature of how to measure consensus or what can be considered consensus. Expressing a summative level of agreement as a percentage is frequently used [59]. In this case, the aims were to explore and reach group consensus about the disability approach taken in London 2012 (items), providing a theory and framework for disability inclusion that could inform future programs [46].

Researchers defined that hypothesis consensus had been reached when the percentage level of respondents giving a 4 (important) or 5 (very important) to each individual item was $\geq 75 \%$ and no new items were being proposed. The likert scale is shown in Table 1 . Percentage levels in other studies have ranged from $70 \%$ upwards $[55,59,60]$.

\subsubsection{Recruitment Strategy}

The individuals involved in the Delphi technique are those who hold expertise and have a deep experience in the area under question. Within the Delphi methodology the group of Panel Members are referred to as 'panel members' $[44,50]$. The number of panel members required can range greatly dependent on the research aim, often being cited anywhere from 10 up to 30 [50,52]. 
Table 1. Likert rating used during rounds 1-3.

\begin{tabular}{cc}
\hline Likert Rating & Significance \\
\hline 1 & Not important at all \\
2 & Slightly unimportant \\
3 & Somewhat important \\
4 & Important \\
5 & Very important \\
\hline
\end{tabular}

For this research, initial panel members were identified by the authors for their significant role in London 2012 and its disability inclusion approach. Snowballing sampling was also used where those initially identified were asked who else should be involved. This methodology has been utilised elsewhere for Delphi recruitment [61-63].

Anonymity is considered a cornerstone of the technique to enable equal opportunity for experts to give opinion without coercion [52,56]. However, anonymity of who else is involved in the research is not always possible due to Panel Members being from a small pool of experts and consequently familiar with each other. In this case, we did not protect anonymity between panel members, and this was apparent once the workshop began with introductions. Nonetheless, anonymity of the individuals' answers is preserved between rounds $[52,56]$, and quotes have been anonymised. The inclusion criteria stipulated that panel members were involved in the planning and implementing of the London 2012 games and its disability inclusion approach, thus they had all worked together before.

In total, 10 Panel Members were involved in rounds 1 and 9 panel members were involved in both rounds 2 and 3. In Delphi methodology, a diminished number of respondents is expected between rounds [54]. In the case of this research collection a panel member sadly passed-away during the time frame between rounds 1 and 2 .

The Panel Members represented the following organisations at various times during the London 2012 Paralympic Games, or immediately after (with many moving between roles): UK Government, Mayor of London, Olympic Delivery Authority, London Organising Committee for the Olympic and Paralympics Games, London Legacy Development Corporation (LLDC), Buro Happold, Poplar Harca (local community organisation), Unlimited (disability arts program), Arts council, British Council, Network Rail and Major Projects Association.

Demographically, $50 \%$ of the Panel Members were male, only $10 \%$ from a BAME background, and $40 \%$ disabled people themselves.

\subsection{Institutional Review Board Statement}

Panel members provided their informed consent for participating in the study in writing with a verbal adaption as a reasonable adjustment for one participant with a visual impairment. The study was conducted in accordance with the Declaration of Helsinki, and the protocol was approved by the UCL Interaction Centre Ethics Committee (ID: UCLIC_1920_011_Staff_Holloway_Williams).

\subsection{Positionality}

The first author (VA) is a white, British-trained postgraduate researcher who lives with two mental health conditions, and who played a significant role as Head of Paralympic Legacy for LLDC from 2008-2017. She conducted the round 1 interviews and led the development of the initial hypothesis A as well as selecting the Panel Members, facilitating the workshop and contributing to thematic analysis. To address objectivity, it was the second author (KM) who designed and oversaw the Delphi and undertook the initial content and thematic analysis. KM is a white, British postgraduate trained researcher who was not involved in London 2012. Finally, $\mathrm{CH}$ a white, Irish, postgraduate trained researcher who was also not involved in delivering London 2012 but is involved in the legacy work of UCL and GDI Hub, supported the thematic analysis and writing. 


\section{Results}

\subsection{Round 1: Interviews and Item Rating \\ 4.1.1. Item Rating}

During round 1 , the panel were interviewed virtually using a semi-structured technique of open and closed ended questions (See Appendix A for interview guide). Closedended questions involved asking each panel member their opinion of the importance of each 'item' to the disability inclusion approach of London 2012 presented in the initial hypothesis $\mathrm{A}$. These were given values using the 5-point Likert-type scale rating question (Table 1). The results were collated, and percentage levels were calculated by taking the number of people who had rated the item as important. Table 2 gives the the percentage levels form Hypothesis A.

Table 2. Percentage levels of item from Hypothesis A.

\begin{tabular}{cc}
\hline $\begin{array}{c}\text { Hypothesis A: Items Significant to the Disability Inclusion } \\
\text { Approach of London } \mathbf{2 0 1 2}\end{array}$ & \% of Panel Members Giving $\mathbf{4}$ or $\mathbf{5}$ \\
\hline 1. Clear mission and joint objective setting & $100 \%$ \\
2. Political leadership & $100 \%$ \\
3. Resources and experts/tools & $100 \%$ \\
4. Management and measurement of objectives & $50 \%^{*}$ \\
5. Public/community backing & $70 \%^{*}$ \\
6. Leadership and involvement of disabled people & $100 \%$ \\
7. Celebrating success & $90 \%$ \\
8. Consequences of failure to act & $80 \%$ \\
9. Innovation & $70 \%$ * \\
\hline
\end{tabular}

* Where percentage level less than $75 \%$.

Three items scored less than the agreed consensus level of $75 \%$ in round 1:

- Management and measurement of objectives (50\%),

- Public/community backing $(70 \%)$ and

- Innovation (70\%).

This resulted in a revised Hypothesis, B, set out in Figure 1, below

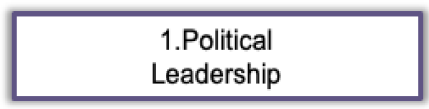

0 . Community leaders' articulation of needs / priorities

11. Time limited action

\section{Reflection \& celebration of} success

9. Scrutiny \& consequences for failure (to act)

2.Clear Mission \& joint objective
setting
setting

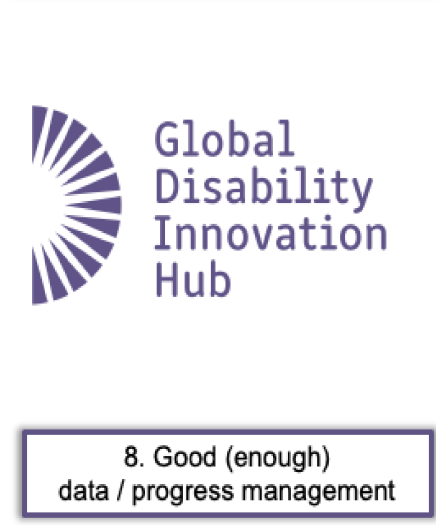

3. Governance by Disabled Leaders \& partners

4. Expert technical assistance \& training

5. Recourses (resourcefulness) and tools

6. Diverse partnerships where everyone drive change

7. Inclusive Innovation encouraged

Figure 1. Hypothesis B.

4.1.2. Exploring the Change between Hypothesis A and Hypothesis B

Thematic analysis allowed the research team to give initial consideration as to why this might be which resulted in a refined set of criteria that make up Hypothesis B.

Two important themes arose at this stage:

Who sets the mission? 
One of the key elements to emerge from this round of the data was the fact that, contrary to belief in Hypothesis A, the mission was not set by the top-level organisations which later adopted it (e.g., The Bid commitments, led by the ODA/Mayor of London, etc.), rather the mission was adopted by this group, having been previously articulated by the community of interest, in this case disabled people and advocates/community originations. This also has resonance with why community backing didn't hit the consensus mark (because the key to the question-community agenda setting - was confused between three items: 1, 6 and 7).

"So I think, I think it's, you know, if you have the whole tapestry, it's a bunch of passionate people who are banging away at whatever it is they're passionate about for years, who grabbed this moment." (PM 1)

This resulted in us amending to add a level 0 , to test whether there was consensus agreement that 'community leader's articulation of needs' came as a pre-courser to political leadership adopting those ideas, then mission setting by leading organisations. It also resulted in the addition of 'governance by disabled leaders and partners' (3).

Time-limited action

The second point that came through strongly in the content analysis of the first round was the importance of time limited action to the London 2012 approach. Management and measurement was felt to be of importance, but time pressure and the will (winning the bid) for that spark to ignite, that came along with it. Panel members said:

"We just felt like if we took a well thought out project to the board ... it was acted on. There wasn't any procrastination going on for months, because we didn't have months." (PM 3)

"[Time] creates a unique morale that 'we are all in this together' and need to deliver, and deliver well, as come the time, the world will be watching!" (PM 1)

This is a theme we return to later when considering the replicability of the model, but for Hypothesis B, this enabled us to add item 11: time limited action. Hypothesis B is set out below, which we used for Round 2 of the research.

\subsubsection{Other Nuanced Changes from Hypothesis A to B}

Between Hypotheses A and B, the content analysis also indicated the following which resulted in nuanced changes:

- Resources and experts/tools came out very strongly as key, and training was especially highlighted. Resources were so central and related to financing and non-financial resources. This resulted in a split out of original item 4 (Resources, experts and Tools) into two new items, 4 (expert technical assistance and training) and 5 (resources and resourcefulness and tools)

- Management and measurement of objectives was not enough alone to resonate with the group, and it was related to both data and the broader category of progress management. There was a strong indication from the group that ongoing research, and a 'trail and test' mechanism should be expressed more clearly. Original item 5 was therefore transformed into Item 8 (good enough data and progress management) in Hypothesis B, and 'innovation' retained.

- Item 6, public and community backing was better expressed as 'Diverse partnership where everyone can drive change'.

- Leadership and involvement of disabled people has been transformed from 7, to new item 0 (to indicate its necessity as a precursor to everything).

- A new, better expressed innovation item was included in Hypothesis B (7) related to the comments made about its importance, despite it not quite making the cut off consensus in round 1 .

- Scrutiny was added to consequences for failure to act-note not failure, but failure to try (9) 
- Reflection was added to celebration of success, to add the idea of reflective celebration of meaningful milestones, rather than mindless cheering of unimportant or fabricated things. Furthermore, to reflect the need for ongoing learning-not everything was got right first time.

\subsection{Round 2: Online Survey Results}

For round 2, each panel member was emailed individualised feedback from round 1 which gave them the calculated percentage levels of each item; some quotes from the interviews; and their original Likert score for each item (See Appendix B). Panel Members were then asked to complete an online survey via Microsoft Forms, and to rate the newly refined items of Hypothesis B using the same Likert rating scale as previously. All Panel Members did this digitally, and one participant was supported to do this verbally by KM as a reasonable adjustment.

Survey results were collated, and the percentage level of agreement was calculated, as before. For round 2 this was determined, sadly, out of 9 survey respondents rather than 10, as previously explained. See Table 3:

Table 3. Percentage levels of item from Hypothesis B.

\begin{tabular}{cc}
\hline Hypothesis B (Tested in Round 2) & \% of Panel Members Giving $\mathbf{4}$ or $\mathbf{5}$ \\
\hline 1. Community leaders' articulation of needs/priorities & $78 \%$ \\
2. Political leadership & $78 \%$ \\
3. Clear mission and joint objective setting & $100 \%$ \\
4. Governance by disabled leaders and partners & $100 \%$ \\
5. Expert technical assistance and training & $78 \%$ \\
6. Resources (resourcefulness) and tools & $100 \%$ \\
7. Diverse partnerships where everyone can drive change & $89 \%$ \\
8. Inclusive innovation encouraged & $89 \%$ \\
9. Good (enough data) and progress management & $89 \%$ \\
10. Scrutiny and consequences of failure to act & $56 \% *$ \\
11. Reflection and celebration of success & $67 \%$ * \\
12. Time limited action-a clear deadline & $89 \%$ \\
\hline
\end{tabular}

* Where percentage level less than $75 \%$.

Hypothesis B scoring was then used, unedited, to structure the discussion in the online workshop in round 3. The two items where consensus had not yet been met informed the focus of the discussion:

- Scrutiny and consequences of failure to act (56\%)

- $\quad$ Reflection and celebration of success $(67 \%)$.

\subsection{Round 3: A Consensus Building Workshop}

\subsubsection{Overview}

The workshop provided opportunity for the panel to reach consensus on items where consensus had not been met and discuss the order and application of the final model. It was also a chance for Panel members to provide additional comments aimed to add to the trustworthiness of the new model in accurately representing the outlined approach.

The workshop began with presentations of the findings of the 2 rounds of the Delphi: Likert scores and thematic analysis results of the semi-structured interviews. The diagram of hypothesis B was presented to the panel. Detailed discussions were held on those themes that had not yet reached consensus. For the full agenda of the workshop please see Appendix C. Final changes are set out below.

\subsubsection{Exploring the Change between Hypothesis B and Hypothesis C}

The following changes resulted:

- Community leader's articulation of needs was adopted into the model (as \#1)

- Time limited action moved up (to 4), as felt critical to set up front (close to objectives) 
- Partnership moved to after governance (6) as they were considered to be interconnected

- Experts (7), Resources (8), Innovation (9) and Data/scrutiny/mgt (10) now sit as a vital and related group

- Culture of excellence (11) was added, this was a reworking of 'consequences of failure to try' and talked to the importance of 'going the extra mile' that permeated all organisations involved-people wanted to do their best.

- We adapted reflection and recognition of success (12) to remove 'celebration' which had a difficult resonance with many Panel Members who felt it could be seen as 'empty' or even 'patronising'.

\subsubsection{Hypothesis C}

Rather pleasingly, this resulted in Hypothesis C, the 12-step model of disability inclusion from London 2012; Figure 2, which was then adopted unanimously by the group.
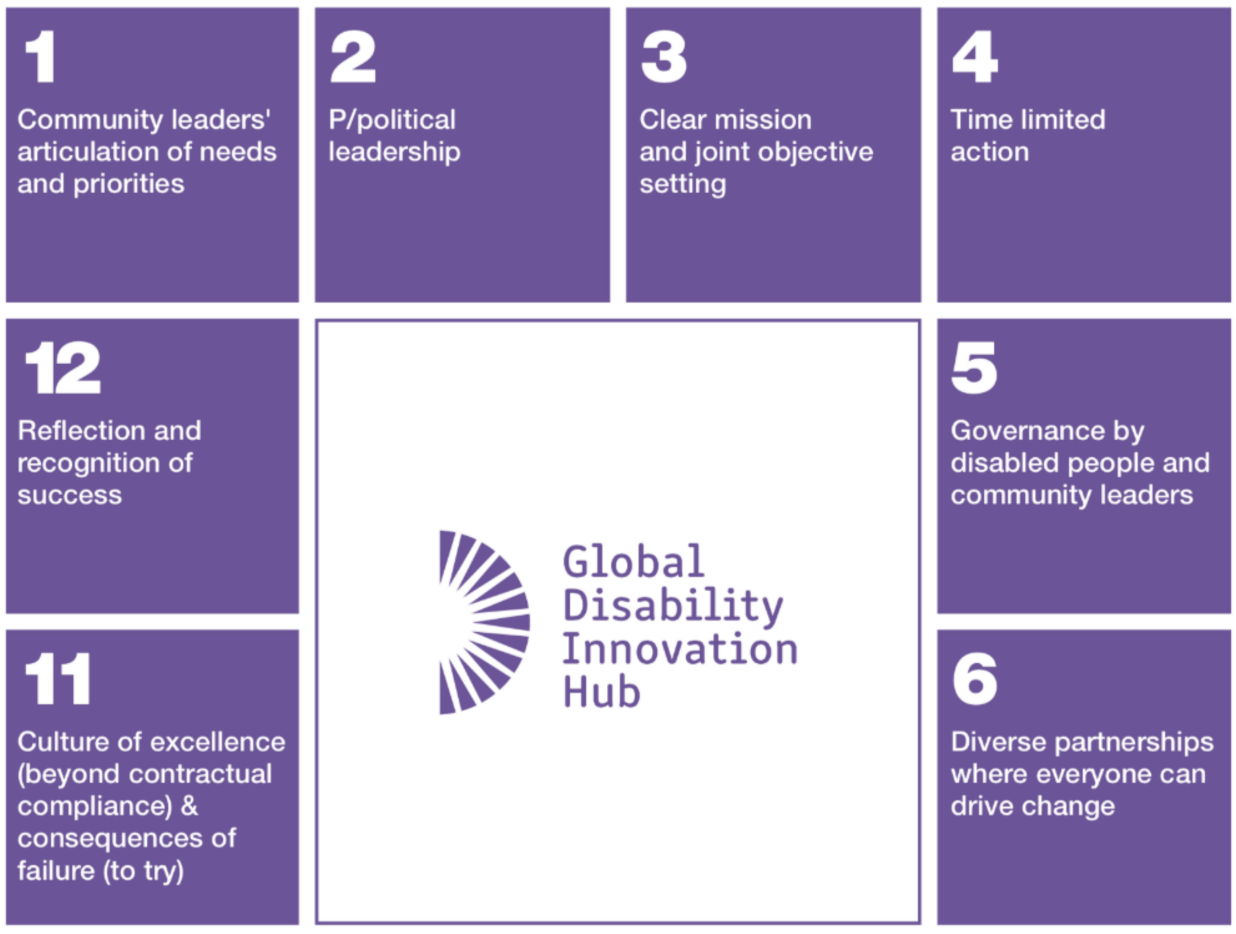

Culture of excellence (beyond contractual compliance) \& consequences of failure (to try)
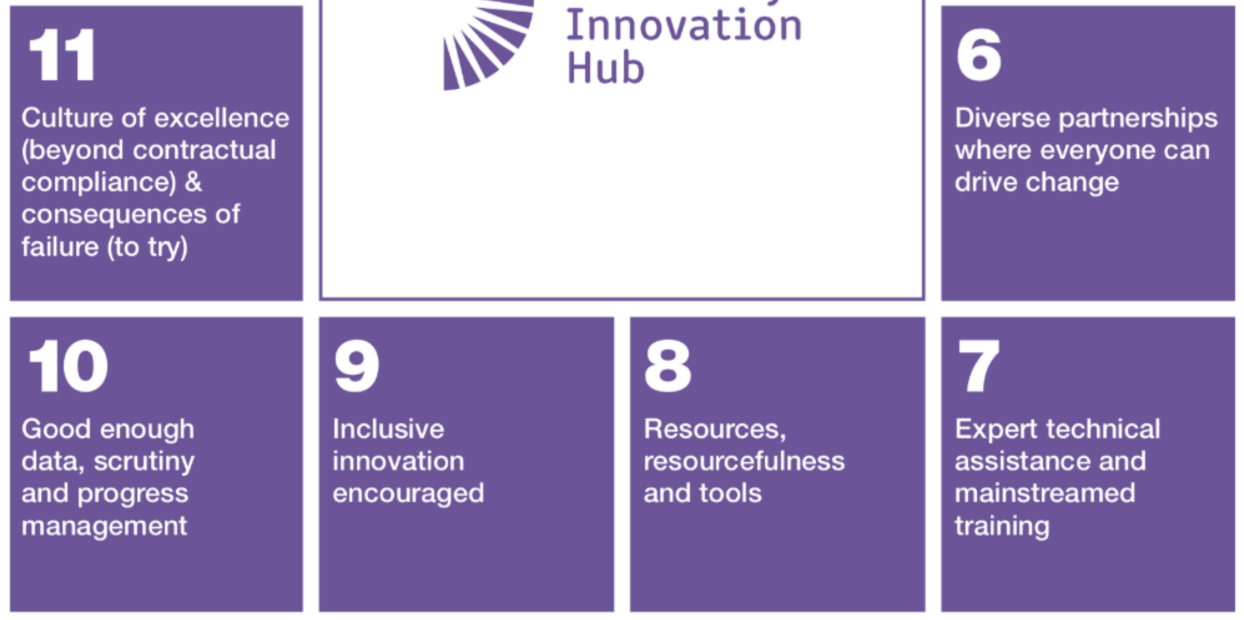

Figure 2. The resulting 12 Step Disability Inclusion Model of London 2012.

\subsubsection{The Relationship between Items and Application to Future Programs}

The consensus workshop also sought to build on initial thinking and inputs from the interviews about the relationship between the items, their choreography and application to future programs. Panel Members believed the relationship between the items often overlapped, and that they were not always necessarily sequential, or linear in order. However, the consensus discussion found sequentiality, and completion of one item before the next was not necessary nor desirable. Further, most steps would stay constantly live throughout, evolving as the project did. There would be differing amounts of time allocated for each and focus would move from one to the next temporarily, retuning to earlier steps somewhat messily throughout. Certain items were unanimously agreed to be essential from 
the outset-the community mission setting for example and the involvement of disabled people and expert technical assistance. However, others could be shaped iteratively as the program developed and more importantly would need ongoing review. This led to grouping into the three parts, with part 1 (get set) completed at the start before the initiative began, or as a first stage, and part 2 (get ready) following a close second, and part 3 (go) would involve more program iteration and would be shaped over time.

\subsection{Building out the Definitions of the Items from the Qualitative Data}

The transcripts from the interview and workshop were analysed to seek evidence for and strengthening the definition of each item in the disability inclusion model. The evidence for each is summarised in Table 4.

Table 4. Building out the definitions of the items from the qualitative data.

\begin{tabular}{ll}
\hline \multicolumn{1}{c}{ Item } \\
\hline \multicolumn{1}{c}{ Part 1} \\
\hline 1. $\quad \begin{array}{l}\text { Community leaders' articulation of } \\
\text { needs and priorities }\end{array}$ \\
2. $\quad \mathrm{P} /$ political leadership \\
3. $\quad \begin{array}{l}\text { Clearly articulated mission and joint ob- } \\
\text { jectives }\end{array}$
\end{tabular}

Part 2

4. Time-limited action

5. Governance by Disabled People and Community Leaders

6. Diverse partnerships where everyone can drive change

7. Expert technical assistance and mainstreamed training.

8. Resources, resourcefulness and tools

\section{Resulting 'Explainer'}

\section{GET READY: Community-LED MISSION SETTING}

The Community of Interest (e.g., disabled people) will already know what issues need to be tackled, and will probably have been campaigning for some time for these issues to be addressed. Transitioning 'external' claims, into a commonly adopted (disability inclusion) mission is a vital stage one.

Both Party Political (big P) support, as well as (small p) political institutional backing are vital to set up the Disability Inclusion mission for success and to align resources to its delivery.

Turning the broad aims of the mission into well understood; regularly articulated; measurable, timed-and agreed-objectives is an important part of the process which raises the profile of the work and gives all interested parties the chance to offer their own contribution.

\section{GET SET: Essential Building Blocks}

For the mission to be successful it should spark interest, maintain momentum, and be delivered according to a timeframe which is fixed.

Co-design of the initial mission by the Community of Interest is not enough, the governance and scrutiny of success should also involve them, alongside key partners responsible for delivery.

It is vital that all key constituencies have the option of being a part of the movement towards the mission because they will bring additional capacity and diversity of thought and approach.

Even the most progressive organisation with the best trained expert-generalists cannot succeed without technical assistance. Ideally this should be 'client side' of

the organisation/s resourcing mission delivery as well as within the delivery agencies. This doesn't negate the need for all staff to receive meaningful, actionable training which is also vital.

Where possible resources should be shared, for economies of scale and so larger partners can support smaller with tools and guides. Resourcefulness will always be required and creative solutions encouraged.

\section{Part 3}

\section{GO: Enabling a Culture of Success}

It is likely at least some of what is needed to deliver the mission has not been done before, so innovation is not optional. It is also a great chance to explore the art of the possible which could leave a lasting legacy and builds a bonded culture of collective learning adding 'the magic in the middle' between what people already know how to do.

Data is always disappointingly difficult, but work with what you have and a blunt instrument can give rise to perverse incentives. However, progress must be

10. Good enough data, scrutiny and progress management mapped, ideally commensurately across stakeholders, and certainly in a way that project managers, communities and decision-makers can track and understand easily. This is the magic that unlocks resources. 
Table 4. Cont.

Item

Resulting 'Explainer'

11. Culture of excellence (beyond contractual compliance) and consequences for failure to try.

12. Reflection and recognition of success
Everyone, no matter their role, is empowered and supported to go the extra mile against the mission. Those who try new things that don't work, are applauded. Those who fail to try at all face penalties.

Reflection ('how are things are going and how they can be improved') builds on a culture of innovation.

Recognition-including through the media and public/community-is offered at regular milestones along the journey.

Both (reflection and recognition) are built regularly into the timeline, not just a feature at the end.

Table 4 sets out the evidence from the thematic analysis and uses this to order the 'items' into three parts. Part 1: Get Ready; Community-led mission setting (which includes the first 3 items); Part 2: Get Set; the essential building blocks (which includes items 4-8); and finally, Part 3; Go setting a culture of success (which includes items 9-12).

\subsubsection{Part 1: 'Get Ready'_Community-Led Mission Setting (Comprising Items 1,2,3)}

The analysis shows that the initial mission setting ideas are created within the Community of Interest and brought into the system by the infiltrators and later adopted by the responsible bodies who also adapt them for their aims. There was universal agreement that this must come first and 'community mission setting' is the first step in embedding meaningful inclusion. This is also a mindful recognition of community knowledge, talent and claims. The evidence for how community leaders articulated the needs and priorities was evident from PM1 who stated:

"This is a story of community leadership with political backing." (PM1)

However, community leadership needed constant explanation and 'battles' for disability inclusion to be understood and undertaken, which as PM2 mentions was a lot of hard work from the ground-up:

"I think it took a lot of hard work on all of us working in the access and inclusive design field. We had a lot of battles all the way through on certain design issues. And but, you know, I think we did damn well really." (PM2)

This hard work took the form of "community leadership and management and reviewing [which] is what gets things done." (PM3)

PM1 went on to explain how the light of disability inclusion grows through:

"a community of interest of individuals, and probably quite small organisations that hold a torch, and that are probably associated with each other in some sorts of ways. And that they banged away and banged away and banged away and bludgeoned this into the official story is my guess." (PM1)

This approach also speaks to taking an opportunity, knowing the cause inside out and then being able to take the opportunity of a large event such as London 2012 to create change:

"So I think, I think it's, you know, if you have the whole tapestry, it's a bunch of passionate people who are banging away at whatever it is they're passionate about for years, who grabbed this moment." (PM1)

This movement of people and ideas can be seen in examples such as Disability advocates feeling they 'infiltrated' institutions to disrupt priorities. The consensus the group had come to on community mission setting included the ability to revisit and refine the mission, but it must be set up front. 


\subsubsection{Part 2: 'Get Set'—The Essential Building Blocks (Comprising Items 4-8)}

The essential building blocks related to the items that were crucial to ensure operational delivery - to the deadline. A strict end point was felt to be necessary in pushing action:

"I think we just felt like if we took a well thought out project to the board, or well thought out ideas for the board. It was acted on. There wasn't any procrastination going on for months, because we didn't have months." (PM 3)

Expertise and skills from diverse partnerships were part of the movement towards the mission delivery because they brought additional capacity and diversity of thought from the very best people.

"You've got to get it right first time. So you've got to bring in the best knowledge, the best experience that you could." (PM 4)

Experts were required to offer technical assistance and to deliver meaningful, actionable training so that every person involved felt empowered and able to drive change.

"When the access consultants and inclusion leads were there it just felt like there was a genuine thirst for that knowledge to embed it and make sure they got it right." (PM 5)

Winning the bid to host the Games had created a tangible resource in both money and the land to build on, that was felt to unlock opportunities. However, these resources alone did not negate the need for resourcefulness;

"That sense of having the vision dream it [what was possible]. [we said] Don't be constrained just by what you think of the resources ... think of how can we bring this [vision to life] centred on resourcefulness." (PM 6)

The co-design of the initial mission by the Community of Interest was not felt to be enough in delivering meaningful impact. Governance and scrutiny by disabled people, from beginning to end, was part of ensuring progress that avoided the mission creeping away from what was initially set out. PM5 said:

"When designs came through BEAP [Built Environment Accessibility Panel], they could actually change it. And ... that was being changed through the voice of local people and local disabled people." (PM 5)

However, as well as mission and building blocks, culture counted too.

\subsubsection{Part 3: Go: Setting a Culture of Success (Comprising Items 9-12)}

Data and progress management were acknowledged as key contributors in mapping what works and evaluating outcomes. Established standards and guidelines were part of this management, so teams and partners could be held accountable and resources could be unlocked. PM 10 commented on the 'balanced scorecard' a tool used by the ODA to keep track on all impacts, financial, environmental and social:

"Keeping track of our progress through a Balanced Scorecard and ID [Inclusive

Design] standard mapping was essential. We worked it through with Deloitte.

Otherwise you end up asking: how useful or beautiful is this?" (PM 10)

The need for strategic planning and commensurate data is clear. However, the panel unanimously felt that the success of London 2012 went beyond good data and was largely due to the creation of a culture of excellence where everyone, no matter their role, was empowered and supported to go the extra mile against the mission and beyond the baseline tick-box requirements. This went beyond contractual compliance, as PM 7 summarised:

"There was a real desire to make a difference and to make a change." (PM 7)

Part of creating a culture of success was about enabling innovation and applauding those who try new things, even if they didn't work. The concept of trying, and failing, was far better than not trying at all (for which consequences were felt): 
"People were open to ways of working and doing things differently and better." (PM 9)

Reflection and recognition of success were needed throughout the project timeline at regular intervals and were considered to be part of an ongoing process of innovation. Recognition was needed through the media and public backing. Reviewing progress was about understanding the learnings and disseminating the findings in a way that could be taken forward-as part of the ongoing journey towards inclusion.

\subsubsection{Part 2: Final Items and Explainers}

The thematic analysis and the consensus on items are brought together in the table below to provide descriptions to illustrate what is meant by each element of the London 2012 12-step inclusion model.

\subsection{Addressing the Questions of Critical Juncture and Replicability}

Our panel recognised that London 2012 was a special case in some ways. However, as Stephen Frost argues in his book based on the case study of London 2012: it is important to focus on the systems that had most effect and this does have wider applicability [64]. For that is how change is made; by learning, embedding and empowering ourselves to do better. One example that was referred to over and over again was the Inclusive Design approach of London 2012, further developed by GDI Hub in legacy, which continues to percolate the designs of major infrastructure projects in the UK and abroad. One panel member commented:

"What was wonderful was coming across the same designers at network rail and them wanting to apply the same principles because they understood why, not because we told them the history lesson, but these guys are designers, they want to know how it works and why it works-we gave them examples." (PM 10)

What is clear is that major events can have an influence on policy and practice, and that this influence can be found in the journey and the learnings along the way as much as in the results of the event itself.

"It's not all about the moment. It's about it's about the journey. And then it's about the learning from the journey." (PM 8)

Panel Members initially felt that the culture of excellence, available resource and morale that the games generated was perhaps difficult to replicate-that perhaps this was a unique moment in time, a critical juncture on which to accelerate disability inclusion forward but hard to repeat. It must be acknowledged-and the panellists did — that the visibility and resources behind London 2012 were considerable. However, when considering each items contribution towards a disability inclusion approach, there was a consensus that these core concepts would be essential and possible to implement in other projects. The chance to creative an inclusive culture that has the possibility of "changing attitudes towards and opportunities for disabled people" (PM 6) was real, tangible and even likely.

The Panel summarised that the London 2012 games could be considered a "a blueprint, where you would look at codifying everything that we did and then have [the solution] out of the box." (PM 6)

In sum, London 2012 was unique, but not matchless, and this paper seeks to hone those elements—above-which can be used to inform other projects.

\section{Discussion}

Mass sporting events such as the Paralympic Games of London 2012 remain of considerable interest to the global community in how they can be leveraged to address social change and contribute towards the realisation of the UN Sustainable Development Goals [65]. As the authors of [66] found, these events have increasingly become part of the 
strategic agenda to forge positive social legacies for marginalised people, and partnerships for leveraging this social impact are becoming a critical component of large scale events [67]. With the advent of the launch of the biggest Human Rights campaign on Disability Inclusion ever, in Tokyo 2021, \#wethe15, sport and major events are a seen as a stronger advocacy tool for disability justice than ever before. However, the role of the Paralympic Games, and initiatives like it, in helping to realise disability inclusion is under-serviced in the literature to date, in part due to the Olympic/Paralympic Legacy being viewed as a "wicked problem" [65] by academia, which lacks case study examples of success (and failure). We set out to offer some further evidence in this space.

Given these complexities, we deployed a Delphi method to develop consensus on the building blocks of the Disability Inclusion Model which was used by London 2012 in order that its applicability beyond may be refined and considered for other major sporting events, as well as to other major programs and global challenges.

The considerable investment in major programmes like London 2012 can bring 'material improvements and to some extent social accessibility' [66] to Cities. However, there is a danger that organisers 'presume and pronounce' [66] that inclusion has been achieved, without a robust methodological approach for implementing such commitments. With the 12-step Disability Inclusion Model (Get ready, Get set, Go) we provide a framework for others to test and build from. As those before us have developed frameworks to help leverage community participation through parasport [17], we put forward our framework as a public good and a 'work in progress' to be shaped by practice.

While there will be no one-size-fits all solution to future global challenges such as delivering inclusion, we believe that when major programs are planning, the first vital step is to listen to the community most affected and to co-construct a joint mission which everyone-no matter their role in the partnership — can support and find a way to be engaged in. In common with the work in [65], we find that the right cross-sector partnership can shape the use of resources, opportunities, and influence leadership and incentives, and our research also supports their findings that engagement, motivation and joint capacity were core factors. We think each of the subsequent steps of the model will be needed to some extent or another in all cases, and we look forward to reading future work which might be better able to assign weightings between the steps for a project or sector. We recommend circling the wheel more than once within any program, as item 12 indicates.

When developing a programs or events as large in scale as the Paralympic Games, it is only natural that a confluence of ideals, ideas and practice combine and occasionally conflict; this is also reflected in how people assess success. Some will point to failures of ableism and a subsequent lack of reach of the inclusion agenda into all communities, post2012. Yet still we offer this model as a base on which to build, in that spirt of the Paralympic values. Through what they achieved and how they have sought to retrospectively frame it for the use of others we salute Panel Members for giving their time to this altruistic pursuit. We concur with the authors of [68] that a culture of inclusive practice (on events and programmes) and more research on disability access and inclusion are needed.

\section{Limitations and Further Research}

The Panel was selected in a limited timeframe and under COVID conditions, and thus there were two other invitees who were not able to participate. Nonetheless, key organisations were well represented. This paper does not set out to measure the impact of London 2012 on Disability Inclusion, and while that is out of scope it would be interesting to test the findings with community organisations and DPOs who participated, and perhaps some which did not, in London 2012.

Finally, as the research indicates, this case study is particular to its setting. Testing whether this model is useful in other contexts, perhaps where the visibility of success is less clear, or resources less available, is something which should be undertaken to prove out its validity beyond London 2012. 


\section{Conclusions}

As \#wethe15 shows, collaboration, legislation and practice surrounding disability inclusion are growing in ambition, reach and robustness. International and national frameworks increasingly offer a structure for Government and non-government organisations alike to design and deliver commitments that recognise and uphold the rights of disabled people.

Key themes were identified across the research field: mainstreaming alongside targeted interventions; an increasing strategic focus at regional and global level patchy implementation locally; and a lack of robustness and dis-census of method, despite an increasing consensus on the importance of disability inclusion. We found data and research generally lacking about effective strategies to implement good disability inclusion thinking in practice, and hence seek to offer London 2012 Paralympic Games as just such a case study.

London 2012 provides an example of a disability inclusive approach which lead to the most inclusive games to date, and this paper capitalises on the unique position of GDI Hub at UCL to review the approach used and learn the lessons such that they might be applied by others, before that knowledge is lost. Beginning with a hypothesis and testing through four rounds of adapted Delphi with ten Panel Member experts, we present here the retrospectively framed 12-step London 2012 Disability Inclusion model for further use and development. We found that while London 2012 was unique, the model is not exclusive, and we believe it is replicable and look forward to seeing this further tested in practice. As new movements like \#wethe15 take shape, we should build in what we have learned from London 2012 and find opportunities to enhance our collective knowledge of 'what works'. Our evidence suggests that the London 2012 Paralympic Legacy represented a step change in what had come before, and as such represents a critical juncture in disability inclusion in practice.

Author Contributions: Conceptualisation, V.A. and C.H.; Methodology V.A., K.M. and C.H.; formal analysis, V.A., K.M., and C.H.; investigation, V.A., K.M. and C.H.; resources, V.A. and C.H. data curation, K.M.; writing—original draft preparation, V.A., C.H. and K.M.; writing-review and editing, V.A., C.H. and K.M. All authors have read and agreed to the published version of the manuscript.

Funding: This research received no external funding and was resourced internally by the Global Disability Innovation Hub.

Institutional Review Board Statement: The study was conducted in accordance with the Declaration of Helsinki, and the protocol was approved by the UCL Interaction Centre Ethics Committee (ID: UCLIC_1920_011_Staff_Holloway_Williams).

Informed Consent Statement: Informed Consent was received from all Panel members.

Data Availability Statement: The study data are available upon request.

Acknowledgments: GDI Hub Advisory Board are thanked for shaping the initial thinking for this paper.

Conflicts of Interest: The authors declare no conflict of interest.

Panel Members Are Gratefully Thanked for Sharing Their Wisdom and Experiences: Paul Brickell, Peter Carr, Karen Elson, Julie Fleck, Margaret Hickish, Lord Chris Holmes, Iain Mckinnon, Neil Smith, Camilla Thrush, Jo Verrant.

\section{Appendix A. Round 1 Interview Guide}

1. By London 2012 I refer to all agencies and individuals involved in delivering the Games and its legacy program, including local communities. Who would you include in that?

2. What is your name and what was/is your role around London 2012?

3. When you reflect on the London 2012 approach to Disability inclusion how well do you think it went? Describe some good examples? How were you involved in them? 
4. What was unique about this compared to other project(s) you have seen before or since?

5. Do you believe the disability inclusion objectives of London 2012 were well understood?

6. Were non-specialist colleagues aware of how they could embed DI? Can you give any examples?

7. What were the main ways in which you observed disability inclusion being systematically included in London 2012 activities?

8. How would the following rate/weight in your opinion, in order of importance?
a. Clear Mission
b. Political buy in
c. Resources \& experts/tools
d. Management and measurement of objectives
e. Public/community backing
f. Leadership and involvement of disabled people
g. Celebrating success
h. Consequences of failure
i. Innovation
j. Anything else?

9. [REVEAL HYPOTHESIS DIAGRAM] How far does this represent what you understand of the disability inclusion approach undertaken by London 2012?

What would you add/amend?

Is there anything missing?

10. What could London 2012 have done better?

Can you give examples?

11. What should future projects consider?

12. Were there non-replicable special circumstances that made the London 2012 approach possible?

Are this really, truly non-replicable?

13. How important was disability inclusion to the overarching mission of London 2012 in your opinion?

14. How much did this influence what happened?

15. Is there anything else you'd like to add?

16. Is there any thing you'd like to ask me?

17. Who else should I talk to?

\section{Appendix B. Round 2-Individualised Feedback Sent to Panel Members Prior to Survey in Round 2}

Your specific ratings of each item for hypothesis $A$ ( $1=$ unimportant, $5=$ very important):

*Example only: this would have been changed depending on the Likert rating given by the panel member in round 1

1. Clear Mission: 4

2. Political buy in: 4

3. Resources \& experts/tools: 4

4. Management and measurement of objectives: 4

5. Public/community backing: 4

6. Leadership and involvement of disabled people: 5

7. Celebrating success: 4

8. Consequences of failure: 4

9. Innovation: 3

Current consensus from round 1, (percentage of group scoring 4 or 5 for each of the items)

1. Clear Mission-100\%

2. Political buy in- $100 \%$

3. Resources \& experts/tools- $100 \%$ 


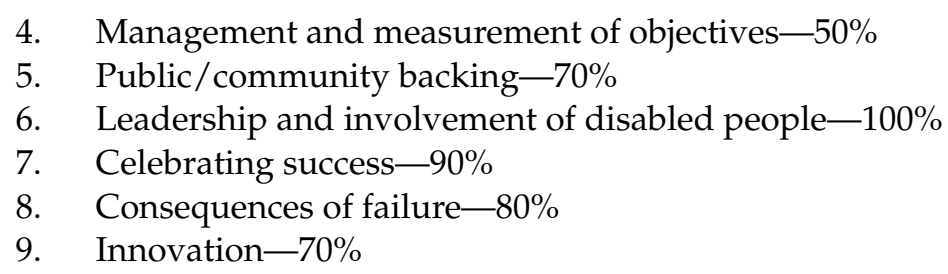

Table A1. Showing unedited, anonymised comments from interviews (round 1) related to each item.

\section{Item}

Clear mission

Political buy in

Resources and experts/tools

Management and measurement of objectives

Public/community backing

Leadership and involvement of disabled people

Celebrating success

\section{Comments from Interviews}

Do you start with an idea, a good idea of the vision. But then when the clarity comes later, decisions are easier. If you have clarity over vision or mission then you are looking to see if decisions add to, deliver to that mission? It can make things more straightforward

I am not sure mission comes first, if you start with a mission, you may not have the same people involved at the beginning. I think you start with an idea, but the scoping of a mission needs verification, ratification, polishing. To move and shift and not be fixed.

Clear mission and joint objectives starts in the community

If you don't get it through cabinet, you haven't got a games. Political buy in critical at beat points all the way through

Buy in-not leadership in the sense of initiative. There is a distinction between buy in and leadership

The problem with political buy in was that you have to have it cross party

Resourcefulness needs to be added-having a sense of seeing the possibility, and then making it a reality

incredibly important and an informed client, will and client intelligence. Client will is one thing then they need to put their money where their mouth is.

Its two different things. I mean measuring things is great but that's not the real thing

General Public were a key client group even if they would never come. Otherwise you have a negative draining resource. I was always after a chance to have everyone as an ambassador as we could convert them

this is a story of community leadership with political backing

community leadership and management is what get things done, and reviewing it. really important because of the daily mail test. Avoid the headline that says disability access costs $£ 20 \mathrm{~m}$.

A lot of the community were against us, about delivering large bits of infrastructure, change. Disability community it was important but there was a lot of distrust about regeneration and not doing what we promised. More about transparency and open dialogue

we don't need to theorise. They've never been disabled volunteers driving before! about the involvement of people with lived experience in every single element of what you're doing. Because if you don't, then you are making the assumption that they can't do that.

because one of the things you have to try to do is get the buy in and stretch the standards in order to recognise others. To give it a 5 you would have to have perfect representation-so it needed to be mediated by professionalism.

It is important, keeps people engaged but learning from failures is more important not over cooking but appreciating, just like a competitor you have to understand the beat points on the journey. Refinement and reflection.

I am not sure about this, I feel like it should be more of a pros and cons it is important [to celebrate success] as thinking about the future is what encourages people to continue to work hard for inclusion-it gives people the chance to understand what can happen.

don't think there was a strong enough review and dissemination of learning. That to me, would have been the real celebration. It becomes easy to fall into the delivery trap. Where it becomes very easy to focus on the things we said we would deliver on. Rather than the celebration we got through it

Being able to clearly demonstrate the added value disability inclusion brings is really important. 
Table A1. Cont.

Item

Consequences of failure

Innovation
Comments from Interviews

There is a huge amount of time people spend pushing blame around in the construction world. Pointing the finger at the architects or the designers or subcontractors. No one ever takes responsibility

I think there is unnecessary time spent on consequences of failure or responsibility of failure-rather than this didn't go right what shall we do next time?

highlighting failure, that's what disabled people have been doing for years, doesn't necessarily work, because it makes people think 'they got away with it' and it encourages people to laugh and provoke no innovation and not trying

Very important learning from failure, understanding when things go wrong critical in every sense, because innovation is enabled by inclusion and innovation you could define as doing stuff differently and therefore without it we wouldn't change attitudes And if we weren't, if we weren't going to have innovation, we weren't going to change attitudes, we weren't going to have the kind of games and the kind of legacy that we all wants to have

I think sometimes we strive so hard to make something innovative. We don't learn the lessons of the past, because we don't feel we can just repeat something that's worked. it stops us embedding what we already know. Ah, search for the endless new when we came across problems we found solutions-otherwise we freeze design and that's been part for the problem for access for a while. Continuous improvement for more and more people

Innovation and change happens locally-from the places that are not official. Bludgeoning your way in.

\section{Appendix C. Round 3 Workshop Agenda}

Meeting Agenda Consensus Building Workshop

Disability Inclusion approach to the London 2012 games

Aims and agenda of the workshop:

1. To agree upon a core set of items that were important in delivering the disability inclusion approach of London 2012:

a. Feedback will be discussed from both the interviews and surveys

b. Discussions about new potential themes-consensus when 'most' people agree $4 / 5$ for each item.

2. To discuss the dynamic relationship between the items and if this it is a linear or circular relationship or something else

3. To discuss to what extent London 2012 games could be considered a 'critical juncture' in disability justice terms and the application to future projects:

a. Was the approach specific to a moment in time with a specific set of circumstances?

b. How could this approach be applied to future projects?

\section{References}

1. United Nations. United Nations Disability Inclusion Strategy; United Nations: Geneva, Switzerland, 2019.

2. Centers for Disease Control and Prevention. Disability \& Health: Disability Inclusion. Available online: https: / / www.cdc.gov / ncbddd/disabilityandhealth/disability-inclusion.html (accessed on 27 January 2021).

3. World Health Organization. World Report on Disability; World Health Organization: Geneva, Switzerland, 2011.

4. United Nations General Assembly. Convention on the Rights of Persons with Disabilities: Resolution/Adopted by General Assembly A/RES/61/106; United Nations General Assembly: New York, NY, USA, 2007.

5. United Nations Sustainable Development Group. Leaving No One Behind A UNSDG Operational Guide for UN Country Teams; United Nations Sustainable Development Group: New York, NY, USA, 2019.

6. International Paralympic Committee. Annual Report 2012; International Paralympic Committee: Bonn, Germany, 2012.

7. London Legacy Development Corporation. Inclusive Design Standards; London Legacy Development Corporation: London, UK, 2013.

8. Baroness Tanni Grey-Thompson. Global Disability Innovation Hub. Inclusive Design Standards Updated for 2019. Available online: https:/ / www.disabilityinnovation.com/news/inclusive-design-standards-updated-for-2019 (accessed on 15 July 2021). 
9. Brittain, I.; Beacom, A. Leveraging the London 2012 Paralympic Games: What Legacy for Disabled People? J. Sport Soc. Issues 2016, 40, 499-521. [CrossRef]

10. SCOPE. Have the Paralympics Improved the Daily Lives of Disabled People? Scope's Blog. Available online: https://blog.scope. org.uk/2013/08/29/have-the-paralympics-improved-the-daily-lives-of-disabled-people/ (accessed on 1 November 2020).

11. Smith, E.M.; MacLachlan, M.; Ebuenyi, I.D.; Holloway, C.; Austin, V. Developing Inclusive and Resilient Systems: COVID-19 and Assistive Technology. Disabil. Soc. 2021, 36, 151-154. [CrossRef]

12. Hepburn, H. "Paralympics Can Raise the Game for Inclusion": News. Available online: https: / /www.proquest.com/docview / 1125223048/402EB6EC16C34A5EPQ/1?accountid=14511 (accessed on 15 July 2021).

13. Misener, L.; Darcy, S.; Legg, D.; Gilbert, K. Beyond Olympic Legacy: Understanding Paralympic Legacy through a Thematic Analysis. J. Sport Manag. 2013, 27, 329-341. [CrossRef]

14. Equality and Human Rights Commission. Public Sector Equality Duty. Available online: https://www.equalityhumanrights. $\mathrm{com} / \mathrm{en} /$ advice-and-guidance/public-sector-equality-duty\#h1 (accessed on 28 January 2021).

15. Gold, J.R.; Gold, M.M. Access for All: The Rise of the Paralympic Games. J. R. Soc. Promot. Health 2007, 127, 133-141. [CrossRef] [PubMed]

16. International Paralympic Committee. International Paralympic Committee Strategic Plan 2019-2022; International Paralympic Committee: Bonn, Germany, 2019; p. 10.

17. Misener, L. Leveraging Parasport Events for Community Participation: Development of a Theoretical Framework. Eur. Sport Manag. Q. 2015, 15, 132-153. [CrossRef]

18. WeThe15. WeThe15-Homepage. Available online: https://www.wethe15.org/ (accessed on 15 July 2021).

19. The London Organising Committee of the Olympic Games and Paralympic Games Limited. The London Organising Committee of the Olympic Games and Paralympic Games; The London Organising Committee of the Olympic Games and Paralympic Games Limited: London, UK, 2005; Volume 1.

20. Perren, K.; Roberts, S.; Stafford, B.; Hirsch, D. Evaluation of the Implementation of the Equality Act 2010: Report 2-Awareness and Impact of the Equality Act; University of Nottingham: London, UK, 2012.

21. Olympic Delivery Authority. Olympic Delivery Authority Integrated Equality Scheme 2009-2012; Olympic Delivery Authority: London, UK, 2009.

22. London Legacy Development Corportation. Equality and Inclusion Policy; London Legacy Development Corportation: London, UK, 2012.

23. Cabinet Office. Inspired by 2012: The Legacy from the Olympic and Paralympic Games: Fourth Annual Report-Summer 2016; Cabinet Office: London, UK, 2016.

24. Olympic and Paralympic Legacy. Convergence: Strategic Regeneration Framework An Olympic Legacy for the Host Boroughs; Olympic and Paralympic Legacy: London, UK, 2009.

25. International Paralympic Committee. London 2012 I International Paralympic Committee. Available online: https://www. paralympic.org/london-2012 (accessed on 28 January 2021).

26. Sir Philip Craven. The Paralympic Games and the Promotion of the Rights of Persons with Disabilities I United Nations. In UN Chronicle; United Nations: New York, NY, USA, 2016.

27. Braye, S.; Dixon, K.; Gibbons, T. The 2012 Paralympics and Perceptions of Disability in the UK. In The Impact of the 2012 Olympic and Paralympic Games: Diminishing Contrasts, Increasing Varieties; Dixon, K., Gibbons, T., Eds.; Palgrave Pivot: London, UK, 2015; pp. 15-34. [CrossRef]

28. Mladenov, T. Performativity and the Disability Category: Solving The Zero Theorem. Crit. Soc. 2020, 46, 51-64. [CrossRef]

29. Braye, S.; Dixon, K.; Gibbons, T. "A Mockery of Equality": An Exploratory Investigation into Disabled Activists' Views of the Paralympic Games. Disabil. Soc. 2013, 28, 984-996. [CrossRef]

30. United Nations Educational Scientific and Cultural Organization. Kazan Action Plan. In The Sixth International Conference of Ministers and Senior Officials Responsible for Physical Education and Sport; United Nations Educational Scientific and Cultural Organization: Paris, France, 2017.

31. Department for International Development, Foreign Commonwealth \& Development Office. Global Disability Summit: Commitments. Available online: https:/ / www.gov.uk/government/collections/global-disability-summit-commitments (accessed on 15 July 2021).

32. Asian Development Bank. Road Map for Strengthening Disability Inclusive Development, 2021-2025; Asian Development Bank: Mandaluyong, Philippines, 2021.

33. World Bank Group. Disability Inclusion and Accountability Framework; World Bank Group: Washington, DC, USA, 2018.

34. CBM. Inclusion Made Easy: A Quick Program Guide; CBM: London, UK, 2012.

35. Pearson, C.; Watson, N.; Stalker, K.; Ferrie, J.; Lepiniere, J.; Paterson, K. Mainstreaming the Disability Equality Duty and the Impact on Public Authorities' Working Practices. Soc. Policy Soc. 2011, 10, 239-250. [CrossRef]

36. Miller, C.; Albert, B. Mainstreaming Disability in Development: Lessons from Gender Mainstreaming; Healthlink: London, UK, 2005.

37. Kuper, H.; Davey, C.; Banks, L.M.; Shakespeare, T. Trials and Tribulations of Collecting Evidence on Effectiveness in DisabilityInclusive Development: A Narrative Review. Sustainability 2020, 12, 7823. [CrossRef] 
38. Ebuenyi, I.D.; Smith, E.M.; Munthali, A.; Msowoya, S.W.; Kafumba, J.; Jamali, M.Z.; MacLachlan, M. Exploring Equity and Inclusion in Malawi's National Disability Mainstreaming Strategy and Implementation Plan. Int. J. Equity Health 2021, 20, 1-8. [CrossRef]

39. Mwendwa, T.N.; Murangira, A.; Lang, R. Mainstreaming the Rights of Persons with Disabilities in National Development Frameworks. J. Int. Dev. 2009, 21, 662-667. [CrossRef]

40. Stough, L.M.; Kang, D. The Sendai Framework for Disaster Risk Reduction and Persons with Disabilities. Int. J. Disaster Risk Sci. 2015, 6, 140-149. [CrossRef]

41. Bennett, D. Five Years Later: Assessing the Implementation of the Four Priorities of the Sendai Framework for Inclusion of People with Disabilities. Int. J. Disaster Risk Sci. 2020, 11, 155-166. [CrossRef]

42. de la Poterie, A.T.; Baudoin, M.A. From Yokohama to Sendai: Approaches to Participation in International Disaster Risk Reduction Frameworks. Int. J. Disaster Risk Sci. 2015, 6, 128-139. [CrossRef]

43. Lee, H.-C.; Chen, H. Implementing the Sendai Framework for Disaster Risk Reduction 2015-2030: Disaster Governance Strategies for Persons with Disabilities in Taiwan. Int. J. Disaster Risk Reduct. 2019, 41, 2212-4209. [CrossRef]

44. McMillan, S.S.; King, M.; Tully, M.P. How to Use the Nominal Group and Delphi Techniques. Int. J. Clin. Pharm. 2016, 38, 655-662. [CrossRef]

45. van Zolingen, S.J.; Klaassen, C.A. Selection Processes in a Delphi Study about Key Qualifications in Senior Secondary Vocational Education. Technol. Forecast. Soc. Chang. 2003, 70, 317-340. [CrossRef]

46. Brady, S.R. Utilizing and Adapting the Delphi Method for Use in Qualitative Research. Int. J. Qual. Methods 2015, 14, 1609406915621381. [CrossRef]

47. Fletcher, A.J.; Marchildon, G.P. Using the Delphi Method for Qualitative, Participatory Action Research in Health Leadership. Int. J. Qual. Methods 2014, 13,1-8. [CrossRef]

48. Renyi, M.; Hegedüs, A.; Maier, E.; Teuteberg, F.; Kunze, C. Toward Sustainable ICT-Supported Neighborhood Development-A Maturity Model. Sustainability 2020, 12, 9319. [CrossRef]

49. Noh, H.; Lee, S.; Yu, J. Identifying Effective Fugitive Dust Control Measures for Construction Projects in Korea. Sustainability 2018, 10, 1206. [CrossRef]

50. Delbecq, A.L. Group Techniques for Program Planning: A Guide to Nominal Groups and Delphi Process; Scott Foresman Company: Glenview, IL, USA, 1975.

51. Toma, C.; Picioreanu, I. The Delphi Technique: Methodological Considerations and the Need for Reporting Guidelines in Medical Journals. Int. J. Public Heal. Res. 2016, 4, 47-59.

52. Ogbeifun, E.; Agwa-Ejon, J.; Mbohwa, C.; Pretorius, J.H.C. The Delphi Technique: A Credible Research Methodology. In International Conference on Industrial Engineering and Operations Management; Ogbeifun, E., Agwa-Ejon, J., Eds.; Kuala Lumpar, Malaysia. 2016. Available online: http:/ /ieomsociety.org/ieom_2016/pdfs/589.pdf (accessed on 15 July 2021).

53. Campbell, S.M.; Cantrill, J.A.; Roberts, D. Prescribing Indicators for UK General Practice: Delphi Consultation Study. BMJ 2000, 321, 425-428. [CrossRef] [PubMed]

54. Homberg, A.; Klafke, N.; Loukanova, S.; Glassen, K. Findings from a Three-Round Delphi Study: Essential Topics for Interprofessional Training on Complementary and Integrative Medicine. BMC Complement. Med. Ther. 2020, 20, 1-13. [CrossRef]

55. Duncan, E.; O'Cathain, A.; Rousseau, N.; Croot, L.; Sworn, K.; Turner, K.M.; Yardley, L.; Hoddinott, P. Guidance for Reporting Intervention Development Studies in Health Research (GUIDED): An Evidence-Based Consensus Study. BMJ Open 2020, 10, e033516. [CrossRef]

56. Keeney, S.; Hasson, F.; McKenna, H. The Delphi Technique in Nursing and Health Research; John Wiley \& Sons, Ltd.: Chichester, UK, 2011.

57. London 2012 Olympic and Paralympic Games. [ARCHIVED CONTENT] Learning Legacy I London 2012. Available online: https: //webarchive.nationalarchives.gov.uk/20180426101359/http:/ / learninglegacy.independent.gov.uk/ (accessed on 15 July 2021).

58. Braun, V.; Clarke, V. Successful Qualitative Research: A Practical Guide for Beginners; SAGE Publications: London, UK, 2013.

59. Stewart, D.; Gibson-Smith, K.; MacLure, K.; Mair, A.; Alonso, A.; Codina, C.; Cittadini, A.; Fernandez-Llimos, F.; Fleming, G.; Gennimata, D.; et al. A Modified Delphi Study to Determine the Level of Consensus across the European Union on the Structures, Processes and Desired Outcomes of the Management of Polypharmacy in Older People. PLoS ONE 2017, 12, e0188348. [CrossRef]

60. Vogel, C.; Zwolinsky, S.; Griffiths, C.; Hobbs, M.; Henderson, E.; Wilkins, E. A Delphi Study to Build Consensus on the Definition and Use of Big Data in Obesity Research. Int. J. Obes. 2019, 43, 2573-2586. [CrossRef] [PubMed]

61. Schaffalitzky, E.; Gallagher, P.; Maclachlan, M.; Wegener, S.T. Developing Consensus on Important Factors Associated with Lower Limb Prosthetic Prescription and Use. Disabil. Rehabil. 2012, 34, 2085-2094. [CrossRef]

62. Goodyear-Smith, F.; Bazemore, A.; Coffman, M.; Fortier, R.D.; Howe, A.; Kidd, M.; Phillips, R.; Rouleau, K.; Van Weel, C. Primary Care Research Priorities in Low-and Middle-Income Countries. Ann. Fam. Med. 2019, 17, 31-35. [CrossRef]

63. Salazar-Elena, J.C.; Sánchez, M.P.; Otamendi, F.J. A Non-Parametric Delphi Approach to Foster Innovation Policy Debate in Spain. Sustainability 2016, 8, 487. [CrossRef]

64. Frost, S. The Inclusion Imperative: How Real Inclusion Creates Better Business and Builds Better Societies; Kogan Page: London, UK, 2014. 
65. Byers, T.; Hayday, E.J.; Mason, F.; Lunga, P.; Headley, D. Innovation for Positive Sustainable Legacy From Mega Sports Events: Virtual Reality as a Tool for Social Inclusion Legacy for Paris 2024 Paralympic Games. Front. Sports Act. Living 2021, 3, 10. [CrossRef] [PubMed]

66. McGillivray, D.; McPherson, G.; Misener, L. Major Sporting Events and Geographies of Disability. Urban Geogr. 2018, 39, 329-344. [CrossRef]

67. Misener, L.; Di Lu, L.; Carlisi, R. Leveraging Events to Develop Collaborative Partnerships: Examining the Formation and Collaborative Dynamics of the Ontario Parasport Legacy Group. J. Sport Manag. 2020, 34, 447-461. [CrossRef]

68. Darcy, S. Disability, Access, and Inclusion in the Event Industry: A Call for Inclusive Event Research. Event Manag. 2012, 16, 259-265. 